\title{
Association of NT-proBNP and GDF-15 with markers of a prothrombotic state in patients with atrial fibrillation off anticoagulation
}

\author{
Paweł T. Matusik $^{1,2}$ (D) Barbara Małecka ${ }^{1,2}$ (D) Jacek Lelakowski ${ }^{1,2}$ (D) $\cdot$ Anetta Undas ${ }^{2,3}$ (D)
}

Received: 3 April 2019 / Accepted: 26 June 2019 / Published online: 6 July 2019

(c) The Author(s) 2019

\begin{abstract}
We investigated whether growth differentiation factor-15 (GDF-15), also known as macrophage inhibitory cytokine-1 (MIC1), levels are associated with a prothrombotic state in atrial fibrillation (AF) as compared to N-terminal pro-B-type natriuretic peptide (NT-proBNP) and high-sensitivity cardiac troponin I (cTnI-hs). In 103 patients with AF assessed off anticoagulation (age: 71.0 [65.0-76.0] years; $\mathrm{CHA}_{2} \mathrm{DS}_{2}$-VASc score: $4.6 \pm 1.7$ ), we measured endogenous thrombin potential (ETP), plasma fibrin clot permeability ( $K_{\mathrm{s}}$, a measure of clot density) and clot lysis time (CLT) and other hemostatic parameters, along with GDF-15, NT-proBNP, and cTnI-hs. GDF-15 positively correlated with ETP and CLT $(r=0.25, P=0.01$ and $R=0.56, P<0.0001$, respectively) but not with $K_{\mathrm{s}}$, von Willebrand factor, thrombin-activatable fibrinolysis inhibitor, plasminogen, antiplasmin or tissue-type plasminogen activator antigen. NT-proBNP showed a stronger association with ETP $(r=0.60, P<0.0001)$ and a similar correlation with CLT $(R=0.53, P<0.0001)$, while cTnI-hs correlated solely with CLT $(R=0.25, P=0.01)$. After adjustment for clinical and laboratory parameters, GDF-15 was a better independent predictor of CLT (unstandardized coefficient $B$ 0.009; 95\% confidence interval [CI] 0.006-0.012) than NT-proBNP $(B 0.007 ; 95 \%$ CI $0.004-0.010, R(2)=0.51 ; P<0.0001)$; while among the three biomarkers, only NT-proBNP was an independent predictor of ETP. Elevated GDF-15 and NT-proBNP independently predict impaired fibrin clot lysability, while NT-proBNP is a key predictor of heightened thrombin formation in AF. Our findings suggest that a predictive value of NT-proBNP and GDF-15 in AF could be in part attributed to their association with prothrombotic blood alterations.
\end{abstract}

\section{Graphic Abstract}

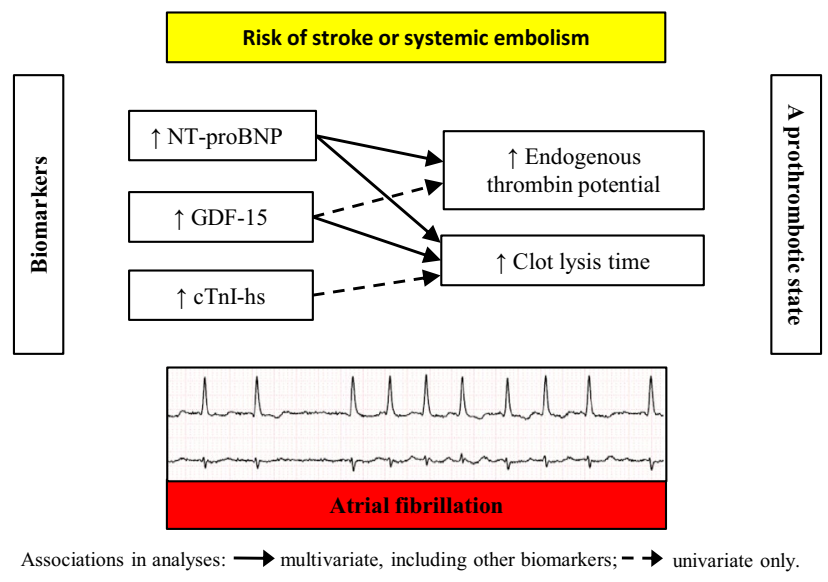

Electronic supplementary material The online version of this article (https://doi.org/10.1007/s00392-019-01522-x) contains supplementary material, which is available to authorized users.

Extended author information available on the last page of the article 
Keywords Atrial fibrillation · NT-proBNP · GDF-15 · Cardiac troponin · Fibrinolysis · Thrombin generation

\section{Introduction}

Atrial fibrillation (AF) increases the risk of stroke and systemic thromboembolism. Their current prediction scores are based on clinical variables. Increasing amount of data indicates the potential of cardiac biomarkers to improve prediction of outcomes in patients with AF [1,2]. Recently, in AF $\mathrm{N}$-terminal pro-B-type natriuretic peptide (NT-proBNP) and high-sensitivity cardiac troponin (cTn-hs) have been shown to be strong and independent predictors of thromboembolism and when combined with clinical data, improve stroke risk assessment [3, 4]. Moreover, the two biomarkers have been reported to be associated with a prothrombotic state in $\mathrm{AF}[5,6]$. In addition, in patients with $\mathrm{AF}$ on anticoagulation, NT-proBNP was not an independent predictor of major bleeding $[7,8]$.

Growth differentiation factor-15 (GDF-15), also known as macrophage inhibitory cytokine-1 (MIC-1), along with NT-proBNP, cTn-hs, age and heart failure diagnosis, have been reported to predict death in AF [9]. GDF-15 in anticoagulated patients with AF has been found to be strongly associated with increased risk of major bleeding, independently of cardiovascular risk factors and other biomarkers, but only in these complex models, it was not associated with stroke/systemic embolism risk [8, 10-12]. Moreover, there is evidence linking GDF-15 with left atrial/left atrial appendage thrombus presence in AF [13].

Mechanisms linking GDF-15 with thromboembolism in $\mathrm{AF}$ are unknown. We investigated the relationship between GDF-15 with prothrombotic abnormalities in AF patients compared with NT-proBNP and high-sensitivity cardiac troponin I (cTnI-hs).

\section{Methods}

In a cross-sectional study, we evaluated patients with $\mathrm{AF}$. We excluded individuals with myocardial infarction or venous thromboembolism within the previous 3 months, kidney failure requiring dialysis or creatinine clearance $<15 \mathrm{~mL} / \mathrm{min}$, liver cirrhosis, known cancer and acute infection. Comorbidities and clinical scores were assessed as described $[5,6]$. The study protocol was approved by bioethical committee and all patients gave informed consent to participate in the study.

Demographic and clinical data were collected at enrolment. Conventional techniques were used to perform transthoracic echocardiography. Fasting venous blood samples were collected in patients off oral anticoagulation. In patients on oral anticoagulants, who were switched to lowmolecular-weight heparin, blood collection was performed after at least $12 \mathrm{~h}$ since the last heparin injection. None of the patients received anticoagulation treatment on the day of the study, as reported previously [5]. Apart from routine laboratory investigations, electrochemiluminescence immunoassays (Roche Diagnostics, Mannheim, Germany) were used to measure GDF-15 and NT-proBNP levels. Serum concentrations of cTnI-hs were determined using the ARCHITECT i1000SR (Abbott Laboratories, Abbott Park, IL, USA). Latex immunoassay using a STAR coagulation instrument (Diagnostica Stago, Asnières, France) was used to measure von Willebrand factor (vWF) antigen. Plasma tissue-type plasminogen activator (tPA), plasminogen activator inhibitor-1 (PAI-1) antigen and thrombin-activatable fibrinolysis inhibitor (TAFI) antigen were measured by ELISAs (American Diagnostica, Stamford, Connecticut, USA and Chromogenix, Lexington, Massachusetts, USA). Antiplasmin and plasminogen were determined using chromogenic assays (Diagnostica Stago).

Measurement of endogenous thrombin potential (ETP) was performed using calibrated automated thrombography (CAT; Thrombinoscope BV, Maastricht, the Netherlands) in a 96-well plate fluorometer (Ascent Reader, Thermolat Systems OY, Helsinki, Finland) at $37{ }^{\circ} \mathrm{C}$, as previously described $[5,14,15]$. Briefly, $80 \mu \mathrm{L}$ of platelet-poor plasma was diluted with $20 \mu \mathrm{L}$ of tissue factor (TF)-based activator (Diagnostica Stago, Asnières, France) containing 5 pmol $\mathrm{L}^{-1}$ recombinant TF, 4 micromolar phosphatidylserine/ phosphatidylcholine/phosphatidylethanolamine vesicles and FluCa solution (20 $\mu \mathrm{L}$; HEPES, pH 7.35, $100 \mathrm{nmol}$ $\mathrm{L}^{-1} \mathrm{CaCl}_{2}, 60 \mathrm{mg} \mathrm{mL}^{-1}$ bovine albumin and $2.5 \mathrm{mmol} \mathrm{L}^{-1}$ Z-Gly-Gly-Arg-amidometylcoumarin). ETP was measured twice [16].

The pore size in fiber networks is indicated by clot permeability. It is proportional to a volume of buffer percolating through a clot under a specific hydrostatic pressure. Assessment of clot permeability was described previously in detail $[5,17]$. Briefly, $20 \mathrm{mmol} / \mathrm{L}$ calcium chloride and $1 \mathrm{U} / \mathrm{mL}$ of human thrombin (Sigma) were added to citrated plasma. Tubes with clots were joined with a reservoir of Tris-buffered saline $(0.1 \mathrm{~mol} / \mathrm{L} \mathrm{NaCl}, 0.01 \mathrm{~mol} / \mathrm{L}$ Tris, $\mathrm{pH} 7.5)$. The volume flowing for $60 \mathrm{~min}$ through the gels was measured. The average size of fiber network pores is reflected by the permeation coefficient $\left(K_{\mathrm{s}}\right) . K_{\mathrm{s}}$ was calculated using the following equation:

$K_{\mathrm{s}}=Q \times L \times \eta / t \times A \times \Delta p$,

where $Q$ is the flow rate in time, $L$ is the length of a fibrin gel, $\eta$ is the viscosity of liquid in poise, $t$ is percolating time, 
$A$ is the cross-sectional area in $\mathrm{cm}^{2}, \Delta p$ is a differential pressure in dyne $/ \mathrm{cm}^{2}$.

The turbidity method was used to determine plasma clot lysis time (CLT), as described previously [5, 17]. Briefly, citrated plasma was mixed with $15 \mathrm{mmol} / \mathrm{L}$ calcium chloride, human tissue factor (10,000-diluted; Innovin, Siemens) at a final concentration of $0.6 \mathrm{pmol} / \mathrm{L}$, phospholipid vesicles $(12 \mu \mathrm{mol} / \mathrm{L})$ and recombinant tPA $(60 \mathrm{ng} / \mathrm{mL}$; Boehringer Ingelheim, Ingelheim, Germany). Measurements were performed at $405 \mathrm{~nm}$ at $37{ }^{\circ} \mathrm{C}$. The midpoint of the clearto-maximum-turbid transition indicated clot formation. Therefore, measurement from this time to the midpoint of the maximum-turbid-to-clear transition was defined as CLT.

Continuous variables were expressed as the mean \pm standard deviation or median (interquartile range). Normality was assessed using the Shapiro-Wilk test. We stratified patients by median GDF-15 level into two groups, i.e., below (low GDF-15) and above or equal to the median of GDF-15 level (high GDF-15). Continuous variables were compared using Student $t$ test or Mann-Whitney $U$ test, as appropriate. Correlations were tested using a linear Pearson correlation or Spearman rang test, as appropriate. Categorical variables were described by number (frequency) and compared by Pearson $\chi^{2}$ test or Fisher's exact test (if more than $20 \%$ of the cells had an expected count of less than 5 and/or if minimum expected count in the particular table was less than 1) [18]. To assess predictors of ETP and CLT, we performed linear regression analysis. $R^{2}$ was calculated, and model adequacy assessment using $F$ test was performed. $P$ values $<0.05$ were considered statistically significant. All statistical analyses were performed with IBM SPSS Statistics (version 24).

\section{Results}

The study group included 103 patients (women, 44.7\%; median age 71 [65-76] years) with the mean $\mathrm{CHA}_{2} \mathrm{DS}_{2}$-VASc score of $4.6 \pm 1.7$ (Table 1). Ninety-nine patients $(96.1 \%)$ had at least two additional (beyond sex) clinical stroke risk factors. The median GDF-15 was 1661.0 (1094.0-2417.0) $\mathrm{pg} / \mathrm{mL}$. GDF-15 correlated with age and body mass index $(R=0.25, P=0.01$ and $R=-0.24$, $P=0.01$, respectively), but not with sex or $\mathrm{CHA}_{2} \mathrm{DS}_{2}$-VASc score. Patients with high GDF-15 $(\geq 1661.0 \mathrm{pg} / \mathrm{mL}) \mathrm{did}$ not differ from the remaining subjects with regard to the type of AF, comorbidities or medications used except for lower prevalence of diabetes and lower use of torasemide in the former group (Table 1). However, patients with diabetes mellitus, those using oral hypoglycemic drug or insulin did not differ from the remainder with regards to GDF-15 level (1491.0 [1075.0-1861.0] vs. 1727.0 [1073.3-2452.5] pg/mL, $P=0.30 ; 1526.0$ [1042.0-1867.5] vs. 1705.0 [1094.0-2449.0] $\mathrm{pg} / \mathrm{mL}, P=0.49$ and 1415.0
[940.8-2586.5] vs. 1684.0 [1129.3-2425.0] pg/mL, $P=0.61$, respectively). We observed a trend towards inverse correlation between glomerular filtration rate (GFR) and GDF-15 $(R=-0.14, P=0.16)$. Lower fibrinogen and glucose levels were found in patients with high GDF-15, while high-density lipoprotein cholesterol was higher in this group (Supplementary Table S1). GDF-15 tended to inversely correlate with white blood cell count $(R=-0.17 ; P=0.08)$ and correlated with NT-proBNP $(R=0.27, P=0.006)$ and cTnIhs $(R=0.28, P=0.004)$.

Analysis of thrombin generation showed that there is a weak positive association of GDF-15 with ETP $(r=0.25$, $P=0.01$; Table 2). ETP strongly correlated with NT-proBNP $(r=0.60 ; P<0.0001)$ and tended to correlate with cTnI-hs $(r=0.19, P=0.05)$. On linear regression analysis, NTproBNP (standardized coefficient $\beta 0.60$; unstandardized coefficient $B 0.08$; 95\% confidence interval [CI] 0.06-0.10, $\left.R^{2}=0.36 ; P<0.0001\right)$ and GDF-15 $(\beta 0.25 ; B 0.03 ; 95 \% \mathrm{CI}$ $\left.0.008-0.060, R^{2}=0.06 ; P=0.01\right)$, but not cTnI-hs $(\beta 0.19$; $B 11.12$; 95\% CI $\left.-0.12-22.35, R^{2}=0.04 ; P=0.052\right)$ predicted ETP. However, when NT-proBNP and GDF-15 were assessed together as predictors of ETP, only NT-proBNP remained a significant predictor (Supplementary Table S2). The same was true after adjustment for age, sex, BMI and fibrinogen (Supplementary Table 3) as well as after additional adjustment for coronary artery disease, heart failure/ left ventricular dysfunction, GFR, antiplasmin, PAI-1, TAFI, C-reactive protein (CRP) and cTnI-hs (Table 3).

As expected, $K_{\mathrm{s}}$ correlated with CLT $(r=-0.37$, $P=0.001)$ and fibrinogen $(r=-0.49 ; P<0.0001)$, but was not significantly associated with other cardiovascular biomarkers or fibrinolysis parameters (only trends were observed, data not shown). However, $K_{\mathrm{s}}$ was inversely correlated with white blood cell count and CRP (for both $r=-0.25 ; P=0.01$ ).

Regarding fibrinolysis, GDF-15 showed no association with TAFI, plasminogen, antiplasmin, tPA or PAI-1 antigen (data not shown). GDF-15 correlated with CLT ( $R=0.56$, $P<0.0001$; Fig. 1), but not with $K_{\mathrm{S}}(r=0.01, P=0.89)$. Patients with high GDF-15 had 19.2\% longer CLT (Table 2). NT-proBNP correlated with CLT $(R=0.53, P<0.0001)$, and tended to correlate with $K_{\mathrm{s}}(r=-0.17, P=0.10)$, while cTnI-hs showed weak association with CLT $(R=0.25$, $P=0.01)$. Moreover, CLT correlated with ETP $(r=0.36$, $P=0.0002)$. There was a trend towards correlation between CLT and $\mathrm{CHA}_{2} \mathrm{DS}_{2}$-VASc score $(R=0.18, P=0.07)$, without association with age or BMI (data not shown).

CLT was predicted by GDF-15 $(\beta 0.57 ; B 0.011 ; 95 \%$ CI $\left.0.008-0.014 ; R^{2}=0.33 ; P<0.0001\right)$, NT-proBNP $(\beta$ $0.51 ; B$ 0.009; 95\% CI 0.006-0.012), $R^{2}=0.26 ; P<0.0001$ ) and cTnI-hs $\left(\beta 0.23 ; B\right.$ 1.84; 95\% CI $0.29-3.39, R^{2}=0.05$; $P=0.02$ ). In a model incorporating these three biomarkers, both GDF-15 and NT-proBNP, but not cTnI-hs, predicted 
Table 1 Patient characteristics stratified by median GDF-15 level

\begin{tabular}{|c|c|c|c|c|}
\hline Variable & Whole group, $n=103$ & $\begin{array}{l}\text { Low GDF-15 (445.3-1628.0 pg/ } \\
\mathrm{mL}, n=51)\end{array}$ & $\begin{array}{l}\text { High GDF-15 (1661.0-5163.0 pg/ } \\
\mathrm{mL}, n=52)\end{array}$ & $P$ value \\
\hline \multicolumn{5}{|l|}{ Demographics } \\
\hline Age (years) & $71.0(65.0-76.0)$ & $69.0(64.0-75.0)$ & $73.0(68.0-78.0)$ & 0.01 \\
\hline Male sex, $n(\%)$ & $57(55.3)$ & $29(56.9)$ & $28(53.8)$ & 0.76 \\
\hline BMI $\left(\mathrm{kg} / \mathrm{m}^{2}\right)$ & $28.4(25.5-32.4)$ & $30.2(26.5-33.9)$ & $27.2(25.0-30.3)$ & 0.004 \\
\hline \multicolumn{5}{|l|}{ Type of AF } \\
\hline Paroxysmal AF, $n(\%)$ & $45(43.7)$ & $20(39.2)$ & $25(48.1)$ & 0.61 \\
\hline Persistent AF, $n(\%)$ & $22(21.4)$ & $11(21.6)$ & $11(21.2)$ & \\
\hline Permanent AF, $n(\%)$ & $36(35.0)$ & $20(39.2)$ & $16(30.8)$ & \\
\hline $\begin{array}{l}\text { AF on the day of blood collection, } \\
n(\%)\end{array}$ & $70(68.0)$ & $37(72.5)$ & $33(63.5)$ & 0.32 \\
\hline $\mathrm{CAD}, n(\%)$ & $53(51.5)$ & $28(54.9)$ & $25(48.1)$ & 0.49 \\
\hline COPD, $n(\%)$ & $11(10.7)$ & $5(9.8)$ & $6(11.5)$ & 0.78 \\
\hline \multicolumn{5}{|l|}{ Comorbidities and CVD risk factors } \\
\hline Hypertension, $n(\%)$ & $85(82.5)$ & $43(84.3)$ & $42(80.8)$ & 0.64 \\
\hline Diabetes mellitus, $n(\%)$ & $41(39.8)$ & $26(51.0)$ & $15(28.8)$ & 0.02 \\
\hline Dyslipidemia, $n(\%)$ & $88(85.4)$ & $47(92.2)$ & $41(78.8)$ & 0.06 \\
\hline Smoking history, $n(\%)$ & $37(35.9)$ & $15(29.4)$ & $22(42.3)$ & 0.17 \\
\hline Previous MI, $n(\%)$ & $25(24.3)$ & $14(27.5)$ & $11(21.2)$ & 0.46 \\
\hline Heart failure/LVD, $n(\%)$ & $75(72.8)$ & $38(74.5)$ & $37(71.2)$ & 0.15 \\
\hline Previous stroke, $n(\%)$ & $14(13.6)$ & $5(9.8)$ & $9(17.3)$ & 0.27 \\
\hline CKD stage 3 or $4, n(\%)$ & $29(28.2)$ & $15(29.4)$ & $14(26.9)$ & 0.78 \\
\hline $\mathrm{CHA}_{2} \mathrm{DS}_{2}$-VASc score & $4.6 \pm 1.7$ & $4.5 \pm 1.9$ & $4.6 \pm 1.6$ & 0.71 \\
\hline HAS-BLED score & $2(1-2)$ & $2.0(1.0-2.0)$ & $2.0(1.0-2.0)$ & 0.31 \\
\hline \multicolumn{5}{|l|}{ Medications, $n(\%)$} \\
\hline Beta-blocker & $83(80.6)$ & $44(86.3)$ & $39(75.0)$ & 0.15 \\
\hline ACE-I & $63(61.2)$ & $32(62.7)$ & $31(59.6)$ & 0.75 \\
\hline ARB & $16(15.5)$ & $11(21.6)$ & $5(9.6)$ & 0.09 \\
\hline CCB & $20(19.4)$ & $12(23.5)$ & $8(15.4)$ & 0.30 \\
\hline Aspirin & $32(31.1)$ & $17(33.3)$ & $15(28.8)$ & 0.62 \\
\hline Clopidogrel & $5(4.9)$ & $3(5.9)$ & $2(3.8)$ & $0.68^{*}$ \\
\hline Statin & $75(72.8)$ & $37(72.5)$ & $38(73.1)$ & 0.95 \\
\hline Digoxin & $20(19.4)$ & $6(11.8)$ & $14(26.9)$ & 0.05 \\
\hline Amiodarone & $13(12.6)$ & $6(11.8)$ & $7(13.5)$ & 0.80 \\
\hline Propafenone & $9(8.7)$ & $6(11.8)$ & $3(5.8)$ & $0.32 *$ \\
\hline Oral hypoglycemic drug & $28(27.2)$ & $17(33.3)$ & $11(21.2)$ & 0.17 \\
\hline Insulin & $9(8.7)$ & $6(11.8)$ & $3(5.8)$ & $0.32 *$ \\
\hline Aldosterone antagonist & $26(25.2)$ & $17(33.3)$ & $9(17.3)$ & 0.06 \\
\hline Furosemide & $21(20.4)$ & $10(19.6)$ & $11(21.2)$ & 0.85 \\
\hline Torasemide & $26(25.2)$ & $18(35.3)$ & $8(15.4)$ & 0.02 \\
\hline Hydrochlorothiazide & $11(10.7)$ & $3(5.9)$ & $8(15.4)$ & 0.12 \\
\hline Indapamide & $17(16.5)$ & $11(21.6)$ & $6(11.5)$ & 0.17 \\
\hline \multicolumn{5}{|l|}{ Echocardiographic parameters ${ }^{\mathrm{a}}$} \\
\hline $\operatorname{LVEF}(\%)$ & $47.7 \pm 13.2$ & $48.4 \pm 14.6$ & $47.0 \pm 11.9$ & 0.59 \\
\hline $\mathrm{LVEF} \geq 50 \%, n(\%)$ & $40(39.6)$ & $22(44.0)$ & $18(35.3)$ & 0.80 \\
\hline LA diameter $(\mathrm{cm})$ & $4.6(4.1-5.0)$ & $4.4(4.1-5.0)$ & $4.7(4.1-5.0)$ & 0.33 \\
\hline
\end{tabular}

Data are presented as mean \pm standard deviation or median (interquartile range) or number (percentage)

$A C E-I$ angiotensin-converting enzyme inhibitor, $A F$ atrial fibrillation, $A R B$ angiotensin II receptor blocker, $B M I$ body mass index, $C A D$ coronary artery disease, $C C B$ calcium channel blocker, $C K D$ chronic kidney disease, $C L T$ clot lysis time, $C O P D$ chronic obstructive pulmonary disease, $C V D$ cardiovascular disease, $G D F-15$ growth differentiation factor-15, $L A$ left atrial, $L V D$ left ventricular dysfunction, $L V E F$ left ventricular ejection fraction, $M I$ myocardial infarction, $n$ number

*Fisher's exact test (exact significance, 2-sided)

${ }^{a}$ The data for LVEF and LA diameter were available for 101 and 95 patients, respectively 
Table 2 Laboratory, coagulation and fibrinolysis parameters stratified by median GDF-15 level

\begin{tabular}{|c|c|c|c|c|}
\hline Variable & Whole group, $n=103$ & $\begin{array}{l}\text { Low GDF-15 (445.3-1628.0 pg/ } \\
\mathrm{mL}, n=51)\end{array}$ & $\begin{array}{l}\text { High GDF-15 (1661.0- } \\
5163.0 \mathrm{pg} / \mathrm{mL}, n=52)\end{array}$ & $P$ value \\
\hline \multicolumn{5}{|c|}{ Laboratory parameters } \\
\hline GFR (mL/min) & $73.0(56.0-85.0)$ & $74.0(56.0-85.0)$ & $73.0(53.0-85.3)$ & 0.70 \\
\hline $\mathrm{CRP}(\mathrm{mg} / \mathrm{L})^{*}$ & $1.7(1.0-3.4)$ & $1.7(1.0-3.2)$ & $1.6(1.0-3.6)$ & 0.73 \\
\hline GDF-15 (pg/mL) & $1661.0(1094.0-2417.0)$ & $1094.0(834.2-1413.0)$ & $2407.0(1830.0-3175.8)$ & $<0.0001$ \\
\hline $\begin{array}{l}\text { NT-proBNP } \\
(\mathrm{pg} / \mathrm{mL})\end{array}$ & $721.0(401.0-1396.0)$ & $634.0(440.0-1009.0)$ & $1086.5(398.8-1694.5)$ & 0.09 \\
\hline cTnI-hs (ng/l) & $6.1(5.0-7.5)$ & $5.7(4.6-7.1)$ & $6.4(5.5-8.3)$ & 0.0099 \\
\hline \multicolumn{5}{|c|}{ Coagulation and fibrinolysis parameters } \\
\hline $\operatorname{APTT}(s)$ & $27.8 \pm 3.8$ & $27.5 \pm 4.3$ & $28.0 \pm 3.2$ & 0.48 \\
\hline INR & $1.0(1.0-1.1)$ & $1.1(1.0-1.1)$ & $1.0(1.0-1.1)$ & 0.45 \\
\hline Fibrinogen $(\mathrm{g} / \mathrm{l})^{*}$ & $3.4(2.7-4.1)$ & $3.7(3.2-4.0)$ & $3.2(2.4-4.1)$ & 0.047 \\
\hline vWF:Ag (\%) & $187.0(151.0-234.0)$ & $183.0(135.0-220.0)$ & $190.0(155.8-243.8)$ & 0.22 \\
\hline TAFI:Ag (\%) & $102.0(94.0-113.0)$ & $105.0(95.0-113.0)$ & $100.0(91.0-114.5)$ & 0.51 \\
\hline Plasminogen $(\%)$ & $105.6 \pm 14.3$ & $103.7 \pm 12.5$ & $107.4 \pm 15.7$ & 0.19 \\
\hline Antiplasmin (\%) & $106.0(96.0-115.0)$ & $107.0(96.0-117.0)$ & $103.5(95.0-114.0)$ & 0.70 \\
\hline tPA:Ag (ng/mL) & $7.2(5.7-9.8)$ & $7.0(5.9-8.0)$ & $7.6(5.5-10.3)$ & 0.49 \\
\hline PAI-1:Ag (ng/mL) & $15.6 \pm 4.0$ & $15.4 \pm 3.8$ & $15.8 \pm 4.3$ & 0.67 \\
\hline $\operatorname{ETP}(\mathrm{nM} \times \min )$ & $1488.0(1403.0-1578.0)$ & $1453.0(1374.0-1521.0)$ & $1502.5(1447.8-1610.3)$ & 0.01 \\
\hline$K_{\mathrm{s}}\left(\times 10^{-9} \mathrm{~cm}^{2}\right)$ & $6.6 \pm 0.9$ & $6.6 \pm 0.9$ & $6.6 \pm 0.9$ & 0.69 \\
\hline CLT (min) & $98.0(81.0-109.0)$ & $86.0(76.0-100.0)$ & $102.5(94.3-117.5)$ & $<0.0001$ \\
\hline
\end{tabular}

Data are presented as mean \pm standard deviation or median (interquartile range)

APTT activated partial thromboplastin time, $C L T$ clot lysis time, CRP C-reactive protein, $c T n I-h s$ high-sensitivity cardiac troponin I, ETP endogenous thrombin potential, GFR glomerular filtration rate, INR international normalized ratio, $K_{s}$ clot permeability, NT-proBNP N-terminal proB-type natriuretic peptide, $P A I-1$ plasminogen activator inhibitor-1, TAFI thrombin-activatable fibrinolysis inhibitor, $t P A$ tissue-type plasminogen activator, $v W F$ von Willebrand factor For other abbreviations see Table 1

*The data for fibrinogen and cTnI-hs were available for 101 patients, while the data for CRP were available for 100 patients

Table 3 Multiple regression analysis of predictors of ETP and CLT in patients with atrial fibrillation

\begin{tabular}{lllc}
\hline & $\begin{array}{l}\text { Standardized coef- } \\
\text { ficients } \beta\end{array}$ & $\begin{array}{l}\text { Unstandardized coefficients } \\
B(95 \% \text { confidence interval })\end{array}$ & $P$ value \\
\hline ETP $\left(R^{2}=0.40 ; P<0.0001\right)^{*}$ & & & $<0.0001$ \\
NT-proBNP $(\mathrm{pg} / \mathrm{mL})$ & 0.56 & $0.01(-0.01-0.04)$ & 0.29 \\
GDF-15 $(\mathrm{pg} / \mathrm{mL})$ & 0.10 & & $<0.0001$ \\
CLT $\left(R^{2}=0.51 ; P<0.0001\right)^{*}$ & & $0.007(0.004-0.010)$ & $<0.0001$ \\
NT-proBNP $(\mathrm{pg} / \mathrm{mL})$ & 0.37 & $0.009(0.006-0.012)$ & \\
GDF-15 $(\mathrm{pg} / \mathrm{mL})$ & 0.49 & &
\end{tabular}

*Adjusted for age, sex, BMI, CAD, heart failure/LVD, GFR, antiplasmin, PAI-1, TAFI, CRP, cTnI-hs and fibrinogen. For abbreviations see the description of Tables 1 and 2
CLT (data not shown). GDF-15 and NT-proBNP predicted CLT in unadjusted model (Supplementary Table S2), after adjustment for age, sex, BMI and fibrinogen (Supplementary Table 3) as well as after additional adjustment for coronary artery disease, heart failure/left ventricular dysfunction, GFR, antiplasmin, PAI-1, TAFI, CRP, cTnI-hs (Table 3).

In our cohort vWF, a marker of endothelial dysfunction, showed a weak association with CLT $(R=0.24 ; P=0.01)$, but was not related to the three biomarkers or fibrinolysis parameters (data not shown).

A median of mean heart rate was 75 (70-80) bpm. There was no correlation between $K_{\mathrm{s}}$ and CLT and mean heart rate $(r=0.03, P=0.77$ and $R=-0.03, P=0.78$, respectively). On the day of blood collection, AF was observed in $68.0 \%$ of patients (Table 1 ). There was no difference in $K_{\mathrm{s}}$ in patients with and without AF on the day of blood collection $\left(6.7 \pm 0.9 \times 10^{-9} \mathrm{~cm}^{2}\right.$ vs. $\left.6.5 \pm 0.8 \times 10^{-9} \mathrm{~cm}^{2} ; P=0.42\right)$. 


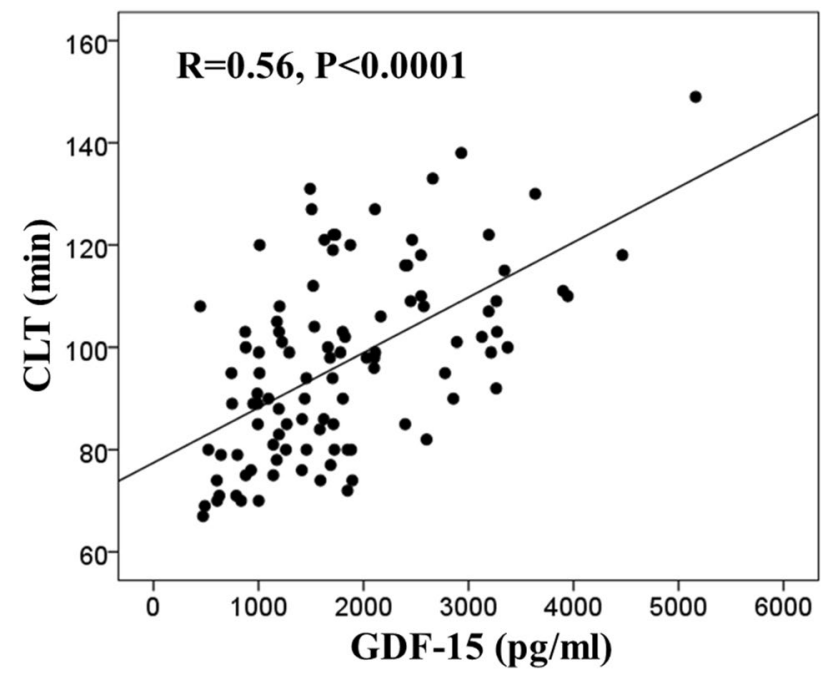

Fig. 1 Correlation of clot lysis time (CLT) with growth differentiation factor-15 (GDF-15) in patients with atrial fibrillation

However, there was a tendency towards prolonged CLT $(99.0$ [83.8-111.3] min vs. 91.0 [78.5-104.5] $\mathrm{min} ; P=0.12$ ) and increased ETP (1495.5 [1433.3-1582.0] $\mathrm{nM} \times \min$ vs. 1450.0 [1327.0-1541.5] $\mathrm{nM} \times \min ; P=0.08$ ) in patients with AF on the day of blood collection, when compared with the remainder.

\section{Discussion}

The present study shows that in nonanticoagulated patients with AF, GDF-15 and NT-proBNP, after adjustment for clinical and laboratory parameters, are the independent predictors of prolonged clot lysis, a measure of plasma fibrinolytic potential. Only NT-proBNP has been observed to independently predict ETP, which suggests that these biomarkers may reflect various aspects of prothrombotic alterations observed in AF. Importantly, this study supports the evidence that elevated biomarkers in AF indicate higher thrombotic risk that cannot be fully explained by age or $\mathrm{CHA}_{2} \mathrm{DS}_{2}$-VASc score. Our findings suggest that a predictive value of the two biomarkers in AF could be in part attributed to their association with prothrombotic blood alterations. However, mechanisms which underlie associations between these biomarkers and thrombotic tendency remain to be established.

We extend our previous observations on associations of NT-proBNP with CLT and ETP [5]. Here, we have shown that associations of NT-proBNP with these surrogate markers of a prothrombotic state are independent of other clinical and laboratory parameters as well as other biomarkers studied (including cTnI-hs and GDF-15). These data might help to explain observations that NT-proBNP is strongly linked to increased risk of stroke/systemic embolism independently of clinical risk factors and cTn-hs [4], but is not independently associated with major bleeding in $\mathrm{AF}[7,8]$.

To our knowledge, there have been no published reports linking GDF-15 levels in circulating blood with specific hemostatic markers in AF, despite the fact that several studies demonstrated that elevated GDF-15 in AF is linked to increased risk of major bleeding, independently of cardiovascular risk factors and other biomarkers $[10,11]$. Some investigators reported an increased risk of stroke or systemic embolism at elevated GDF-15 concentrations in AF patients even on oral anticoagulation [7]. However, a predictive role of GDF-15 in terms of stroke/systemic embolism remains still controversial as evidenced in models when other biomarkers were included, namely NT-proBNP and cardiac troponin $\mathrm{T}$ in the Randomized Evaluation of Long-Term Anticoagulation Therapy (RE-LY) biomarker substudy and NT-proBNP, cardiac troponin I and cystatin C in the Apixaban for Reduction in Stroke and Other Thromboembolic Events in Atrial Fibrillation (ARISTOTLE) trial substudy $[8,10,11]$. In these seminal trials, when multivariable analyses including other biomarkers were performed, GDF-15 was no longer independently associated with stroke/systemic embolism [8, 10, 11]. Expression of GDF-15 is induced by pro-inflammatory cytokines, including tumor necrosis factor (TNF)- $\alpha$, interleukin (IL)- $1 \beta$ and IL-6 [19, 20]. GDF15 exerts anti-inflammatory effects, leading to inhibition of lipopolysaccharide-stimulated secretion of TNF- $\alpha$ by macrophages [19]. Moreover, GDF-15 has been shown to inhibit the activation of $\beta_{1}$ and $\beta_{2}$-integrins on platelets and prevent thrombus formation in mice, with no effect on platelet $\mathrm{P}$-selectin expression and dense granule secretion after stimulation [21]. We observed that GDF-15 tended to inversely correlate with white blood cell count, but we did not find any association of GDF-15 with CRP with even lower fibrinogen at high GDF-15 concentrations, indicating the involvement of proinflammatory mechanisms independent of IL-6. We did not observe relations between GDF-15 and vWF, tPA, or PAI- 1 antigen in our patients with AF. However, in a cohort of elderly patients GDF-15 was found to be weakly or moderately related to vWF, PAI-1 activity and tPA antigen, suggesting that in patients with AF, GDF15 may reflect other prothrombotic alterations [22].

Our key observation reported here is a positive association between GDF-15 and CLT, indicating that processes leading to elevation of GDF-15 drive antifibrinolytic reactions unrelated to increased PAI-1 or antiplasmin. A weak association between GDF-15 and lysis time observed in univariate analysis has been recently reported in patients after acute coronary syndrome (ACS) included in the PLATelet inhibition and patient Outcomes (PLATO) 
trial [23]. It might be speculated that oxidative stress and inflammation $[5,24,25]$ promote both elevation of GDF15 and prothrombotic alterations, rendering both GDF-15 and CLT potentially valuable markers both in AF and after ACS.

It has been shown that formation of denser fibrin clots is associated with increased risk of thromboembolism in patients with AF on oral anticoagulation [26, 27]. Given an inverse association between clot permeability and CLT, it is possible that CLT has a similar prognostic value. In the light of the available data, associations between clinical outcomes and the biomarkers tested are complex. It remains to be explored in a large prospective cohort study whether a predictive value of GDF-15 in terms of morbidity and mortality in AF [7, 9, 10, 13] is in part mediated by suppressed plasma fibrinolytic potential. The independent association of NT-proBNP with both increased ETP and prolonged CLT is consistent with clinical findings indicating that NT-proBNP is more potent than GDF-15 predictor of thromboembolic risk in AF [8]. Our results support the evolving use of biomarkers in more individualized patient-oriented thromboembolic risk stratification in patients with $\mathrm{AF}[8,28]$. It may be hypothesized that these biomarkers may be helpful, not only in diagnostics, but also in prediction of future use or decision-making on introduction of interventional procedures, including cardiac pacing, ablation and/or renal sympathetic denervation [29-37].

Several study limitations should be acknowledged. Since the vast majority of the current patients were at high risk of stroke or systemic thromboembolism, our findings could not be referred to low-risk AF patients or those receiving anticoagulant therapy, known to modify clot properties and decrease thrombin formation [38, 39]. The associations observed do not necessarily mean the cause-effect relationship. Some of the relations tested in the current study, most probably due to relatively low number of patients and confounding factors present (comorbidities and cardiovascular disease risk factors), did not reach statistical significance. Determination of proinflammatory cytokines or oxidative stress markers was beyond the scope of this study. Molecular mechanisms behind the association of elevated GDF-15 with hypofibrinolysis in AF remain to be elucidated.

This study demonstrates that elevated GDF-15 and NTproBNP independently predict low plasma fibrinolytic potential measured in patients with $\mathrm{AF}$ off anticoagulation, while NT-proBNP is a key predictor of heightened thrombin formation in AF. The three key biomarkers measured in AF reflect various specific prothrombotic abnormalities, suggesting that determination of the biomarkers might refine characterization of a hypercoagulable state in AF. This study provides data linking NT-proBNP and GDF-15 with prothrombotic blood alterations, which might support the concept of a value of the biomarkers in the estimation of stroke risk in $\mathrm{AF}$.

Acknowledgements This work was supported by Jagiellonian University Medical College grant (K/ZDS/007717, to A.U.).

\section{Compliance with ethical standards}

Conflict of interest The authors report no relationships that could be construed as a conflict of interest.

Open Access This article is distributed under the terms of the Creative Commons Attribution 4.0 International License (http://creativeco mmons.org/licenses/by/4.0/), which permits unrestricted use, distribution, and reproduction in any medium, provided you give appropriate credit to the original author(s) and the source, provide a link to the Creative Commons license, and indicate if changes were made.

\section{References}

1. Garcia-Fernandez A, Roldan V, Rivera-Caravaca JM, HernandezRomero D, Valdes M, Vicente V, Lip GY, Marin F (2017) Does von Willebrand factor improve the predictive ability of current risk stratification scores in patients with atrial fibrillation? Sci Rep 7:41565. https://doi.org/10.1038/srep41565

2. Glowicki B, Matusik PT, Plens K, Undas A (2019) Prothrombotic state in atrial fibrillation patients with one additional risk factor of the CHA2DS2-VASc score (beyond sex). Can J Cardiol 35(5):634-643. https://doi.org/10.1016/j.cjca.2019.01.014

3. Oldgren J, Hijazi Z, Lindback J, Alexander JH, Connolly SJ, Eikelboom JW, Ezekowitz MD, Granger CB, Hylek EM, Lopes RD, Siegbahn A, Yusuf S, Wallentin L, RE-LY and ARISTOTLE Investigators, Investigators A (2016) Performance and validation of a novel biomarker-based stroke risk score for atrial fibrillation. Circulation 134(22):1697-1707. https://doi.org/10.1161/CIRCU LATIONAHA.116.022802

4. Hijazi Z, Lindback J, Alexander JH, Hanna M, Held C, Hylek EM, Lopes RD, Oldgren J, Siegbahn A, Stewart RA, White HD, Granger CB, Wallentin L, ARISTOTLE and STABILITY Investigators (2016) The ABC (age, biomarkers, clinical history) stroke risk score: a biomarker-based risk score for predicting stroke in atrial fibrillation. Eur Heart J 37(20):1582-1590. https://doi. org/10.1093/eurheartj/ehw054

5. Matusik PT, Matusik PS, Kornacewicz-Jach Z, Malecka B, Zabek A, Undas A (2017) Elevated NT-proBNP is associated with unfavorably altered plasma fibrin clot properties in atrial fibrillation. Int J Cardiol 243:244-250. https://doi.org/10.1016/j.ijcar d.2017.05.060

6. Matusik PT, Prior SM, Butenas S, Malecka B, Lelakowski J, Undas A (2018) Association of cardiac troponin I with prothrombotic alterations in atrial fibrillation. Kardiol Pol 76(7):11061109. https://doi.org/10.5603/KP.2018.0134

7. Berg DD, Ruff CT, Jarolim P, Giugliano RP, Nordio F, Lanz HJ, Mercuri MF, Antman EM, Braunwald E, Morrow DA (2019) Performance of the $\mathrm{ABC}$ scores for assessing the risk of stroke or systemic embolism and bleeding in patients with atrial fibrillation in ENGAGE AF-TIMI 48. Circulation 139(6):760-771. https:// doi.org/10.1161/CIRCULATIONAHA.118.038312

8. Matusik PT (2019) Biomarkers and cardiovascular risk stratification. Eur Heart J 40(19):1483-1485. https://doi.org/10.1093/eurhe artj/ehz265 
9. Hijazi Z, Oldgren J, Lindback J, Alexander JH, Connolly SJ, Eikelboom JW, Ezekowitz MD, Held C, Hylek EM, Lopes RD, Yusuf S, Granger CB, Siegbahn A, Wallentin L, Investigators R-L Aristotle (2018) A biomarker-based risk score to predict death in patients with atrial fibrillation: the ABC (age, biomarkers, clinical history) death risk score. Eur Heart J 39(6):477-485. https://doi. org/10.1093/eurheartj/ehx584

10. Wallentin L, Hijazi Z, Andersson U, Alexander JH, De Caterina R, Hanna M, Horowitz JD, Hylek EM, Lopes RD, Asberg S, Granger CB, Siegbahn A, ARISTOTLE Investigators (2014) Growth differentiation factor 15 , a marker of oxidative stress and inflammation, for risk assessment in patients with atrial fibrillation: insights from the Apixaban for Reduction in Stroke and Other Thromboembolic Events in Atrial Fibrillation (ARISTOTLE) trial. Circulation 130(21):1847-1858. https://doi.org/10.1161/CIRCULATIO NAHA.114.011204

11. Hijazi Z, Oldgren J, Andersson U, Connolly SJ, Eikelboom JW, Ezekowitz MD, Reilly PA, Yusuf S, Siegbahn A, Wallentin L (2017) Growth-differentiation factor 15 and risk of major bleeding in atrial fibrillation: insights from the randomized evaluation of long-term anticoagulation therapy (RE-LY) trial. Am Heart J 190:94-103. https://doi.org/10.1016/j.ahj.2017.06.001

12. Hijazi Z, Oldgren J, Lindback J, Alexander JH, Connolly SJ, Eikelboom JW, Ezekowitz MD, Held C, Hylek EM, Lopes RD, Siegbahn A, Yusuf S, Granger CB, Wallentin L, ARISTOTLE and RE-LY Investigators (2016) The novel biomarker-based $\mathrm{ABC}$ (age, biomarkers, clinical history)-bleeding risk score for patients with atrial fibrillation: a derivation and validation study. Lancet 387(10035):2302-2311. https://doi.org/10.1016/S0140 -6736(16)00741-8

13. Hu XF, Zhan R, Xu S, Wang J, Wu J, Liu X, Li Y, Chen L (2018) Growth differentiation factor 15 is associated with left atrial/left atrial appendage thrombus in patients with nonvalvular atrial fibrillation. Clin Cardiol 41(1):34-38. https://doi.org/10.1002/ clc. 22844

14. Hemker HC, Al Dieri R, De Smedt E, Beguin S (2006) Thrombin generation, a function test of the haemostatic-thrombotic system. Thromb Haemost 96(5):553-561

15. Hemker HC, Kremers R (2013) Data management in thrombin generation. Thromb Res 131(1):3-11. https://doi.org/10.1016/j. thromres.2012.10.011

16. Siudut J, Grela M, Wypasek E, Plens K, Undas A (2016) Reduced plasma fibrin clot permeability and susceptibility to lysis are associated with increased risk of postthrombotic syndrome. J Thromb Haemost 14(4):784-793. https://doi.org/10.1111/jth.13264

17. Meus R, Son M, Sobczyk D, Undas A (2016) Prothrombotic state in patients with a left atrial appendage thrombus of unknown origin and cerebrovascular events. Stroke 47(7):1872-1878. https:// doi.org/10.1161/STROKEAHA.116.012856

18. Bewick V, Cheek L, Ball J (2004) Statistics review 8: qualitative data-tests of association. Crit Care 8(1):46-53. https://doi. org/10.1186/cc2428

19. Bootcov MR, Bauskin AR, Valenzuela SM, Moore AG, Bansal M, He XY, Zhang HP, Donnellan M, Mahler S, Pryor K, Walsh BJ, Nicholson RC, Fairlie WD, Por SB, Robbins JM, Breit SN (1997) MIC-1, a novel macrophage inhibitory cytokine, is a divergent member of the TGF-beta superfamily. Proc Natl Acad Sci USA 94(21):11514-11519. https://doi.org/10.1073/pnas.94.21.11514

20. Desmedt S, Desmedt V, De Vos L, Delanghe JR, Speeckaert R, Speeckaert MM (2019) Growth differentiation factor 15: A novel biomarker with high clinical potential. Crit Rev Clin Lab Sci 56(5):333-350. https://doi.org/10.1080/10408363.2019.1615034

21. Rossaint J, Vestweber D, Zarbock A (2013) GDF-15 prevents platelet integrin activation and thrombus formation. $\mathrm{J}$ Thromb Haemost 11(2):335-344. https://doi.org/10.1111/jth.12100
22. Eggers KM, Kempf T, Lind L, Sundstrom J, Wallentin L, Wollert KC, Siegbahn A (2012) Relations of growth-differentiation factor-15 to biomarkers reflecting vascular pathologies in a population-based sample of elderly subjects. Scand J Clin Lab Invest 72(1):45-51. https://doi.org/10.3109/00365513.2011.626072

23. Sumaya W, Wallentin L, James SK, Siegbahn A, Gabrysch K, Bertilsson M, Himmelmann A, Ajjan RA, Storey RF (2018) Fibrin clot properties independently predict adverse clinical outcome following acute coronary syndrome: a PLATO substudy. Eur Heart J 39(13):1078-1085. https://doi.org/10.1093/eurheartj/ehy013

24. Violi F, Pastori D, Pignatelli P, Loffredo L (2014) Antioxidants for prevention of atrial fibrillation: a potentially useful future therapeutic approach? A review of the literature and meta-analysis. Europace 16(8):1107-1116. https://doi.org/10.1093/europace/ euu040

25. Pignatelli P, Menichelli D, Pastori D, Violi F (2018) Oxidative stress and cardiovascular disease: new insights. Kardiol Pol 76(4):713-722. https://doi.org/10.5603/KP.a2018.0071

26. Drabik L, Wolkow P, Undas A (2017) Fibrin clot permeability as a predictor of stroke and bleeding in anticoagulated patients with atrial fibrillation. Stroke 48(10):2716-2722. https://doi. org/10.1161/STROKEAHA.117.018143

27. Janion-Sadowska A, Chrapek M, Konieczynska M, Undas A (2018) Altered fibrin clot properties predict stroke and bleedings in patients with atrial fibrillation on rivaroxaban. Stroke 50(1):185-188. https://doi.org/10.1161/STROKEAHA.118.02371 2

28. Thomas D, Christ T, Fabritz L, Goette A, Hammwohner M, Heijman J, Kockskamper J, Linz D, Odening KE, Schweizer PA, Wakili R, Voigt N (2019) German Cardiac Society Working Group on Cellular Electrophysiology state-of-the-art paper: impact of molecular mechanisms on clinical arrhythmia management. Clin Res Cardiol 108(6):577-599. https://doi.org/10.1007/s0039 2-018-1377-1

29. Litwinowicz R, Bartus M, Ceranowicz P, Kapelak B, Lakkireddy D, Bartus K (2018) Stroke risk reduction after left atrial appendage occlusion in elderly patients with atrial fibrillation: longterm results. Pol Arch Intern Med 128(5):327-329. https://doi. org/10.20452/pamw.4264

30. Feyz L, Theuns DA, Bhagwandien R, Strachinaru M, Kardys I, Van Mieghem NM, Daemen J (2019) Atrial fibrillation reduction by renal sympathetic denervation: 12 months' results of the AFFORD study. Clin Res Cardiol 108(6):634-642. https://doi. org/10.1007/s00392-018-1391-3

31. Semmler V, von Krogh F, Haller B, Reents T, Bourier F, Telishevska M, Kottmaier M, Kornmayer M, Brooks S, Koch-Buttner K, Lennerz C, Brkic A, Grebmer C, Blazek P, Weigand S, Hessling G, Kolb C, Deisenhofer I (2019) The incidence, indications and predictors of acute pacemaker implantation after ablation of persistent atrial fibrillation. Clin Res Cardiol 108(6):651-659. https://doi.org/10.1007/s00392-018-1393-1

32. Maurer T, Rottner L, Makimoto H, Reissmann B, Heeger CH, Lemes C, Fink T, Riedl J, Santoro F, Wohlmuth P, Volkmer M, Mathew S, Metzner A, Ouyang F, Kuck KH, Sohns C (2018) The best of two worlds? Pulmonary vein isolation using a novel radiofrequency ablation catheter incorporating contact force sensing technology and 56-hole porous tip irrigation. Clin Res Cardiol 107(11):1003-1012. https://doi.org/10.1007/s00392-018-1270-y

33. Matusik PT, Tomala I, Piekarz J, Karkowski G, Kuniewicz M, Lelakowski J (2016) Thyroid goiter: implications for implantation of cardiovascular implantable electronic devices and cannulation of the superior vena cava confluence. Pol Arch Med Wewn 126(6):432-434. https://doi.org/10.20452/pamw.3459

34. de Jong MR, Hoogerwaard AF, Adiyaman A, Smit JJJ, Ramdat Misier AR, Heeg JE, van Hasselt B, Van Gelder IC, Crijns H, 
Lozano IF, Toquero Ramos JE, Javier Alzueta F, Ibanez B, Rubio JM, Arribas F, Porres Aracama JM, Brugada J, Mont L, Elvan A (2018) Treatment of atrial fibrillation in patients with enhanced sympathetic tone by pulmonary vein isolation or pulmonary vein isolation and renal artery denervation: clinical background and study design : the ASAF trial: ablation of sympathetic atrial fibrillation. Clin Res Cardiol 107(7):539-547. https://doi.org/10.1007/ s00392-018-1214-6

35. Buist TJ, Adiyaman A, Smit JJJ, Ramdat Misier AR, Elvan A (2018) Arrhythmia-free survival and pulmonary vein reconnection patterns after second-generation cryoballoon and contactforce radiofrequency pulmonary vein isolation. Clin Res Cardiol 107(6):498-506. https://doi.org/10.1007/s00392-018-1211-9

36. Sohns C, Metzner A, Chmelevsky M, Kuck KH (2018) A new algorithm to visualize the individual relationship between electrical rotors from non-invasive panoramic mapping and atrial fibrosis to guide ablation of persistent atrial fibrillation. Clin Res Cardiol 107(5):444-446. https://doi.org/10.1007/s00392-017-1196-9
37. Santema BT, Kloosterman M, Van Gelder IC, Mordi I, Lang CC, Lam CSP, Anker SD, Cleland JG, Dickstein K, Filippatos G, Van der Harst P, Hillege HL, Ter Maaten JM, Metra M, Ng LL, Ponikowski P, Samani NJ, Van Veldhuisen DJ, Zwinderman AH, Zannad F, Damman K, Van der Meer P, Rienstra M, Voors AA (2018) Comparing biomarker profiles of patients with heart failure: atrial fibrillation vs. sinus rhythm and reduced vs. preserved ejection fraction. Eur Heart J 39(43):3867-3875. https://doi.org/10.1093/ eurheartj/ehy421

38. Zabczyk M, Undas A (2017) Plasma fibrin clot structure and thromboembolism: clinical implications. Pol Arch Intern Med 127(12):873-881. https://doi.org/10.20452/pamw.4165

39. Undas A, Zabczyk M (2018) Antithrombotic medications and their impact on fibrin clot structure and function. J Physiol Pharmacol. https://doi.org/10.26402/jpp.2018.4.02

\section{Affiliations}

\section{Paweł T. Matusik ${ }^{1,2}\left(\right.$ D $\cdot$ Barbara Małecka $^{1,2}$ (D) . Jacek Lelakowski ${ }^{1,2}$ (D) Anetta Undas $s^{2,3}$ (ID}

Anetta Undas

mmundas@cyf-kr.edu.pl

1 Department of Electrocardiology, The John Paul II Hospital, Kraków, Poland
Institute of Cardiology, Jagiellonian University Medical College, 80 Prądnicka Street, 31-202 Kraków, Poland

3 Krakow Center for Medical Research and Technology, The John Paul II Hospital, Kraków, Poland 